CO0-1591-9

UTEC · MSE - 69-157

\title{
CALCULATIONS OF STRAINS AND STRAIN RATES IN BENDING CREEP TESTS ${ }^{\text {' }}$
}

by

G. R. Terwilliger

2

R. S. Gordon

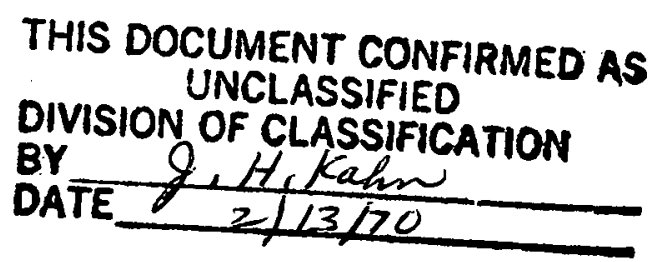

\begin{abstract}
今.
Division of Materials Science and Engineering

University of Utah

Salt Lake City, Utah
\end{abstract}

December 1969

1 Based in part on a thesis submitted by G.R. Terwilliger to the Division of Materials Science and Engineering, University of Utah, in partial fulfillment of the requirements for the Ph.D. Degree.

$2^{2}$

Graduate Research Assistant, Uivision of Materials Science and Engineering, at the time of the work. Presently Senior Scientist, Westinghouse Electric Corporation, Research and Development.Center; Pittsburgh, Pennsylvania. 3

Associate Professor, Uivision of Materials Science and Engineering, University of Utah.

Thts report was prepared as an account of Government sponsored work. Netther the Unttod States, nor the Comminoton, nor any parson actupg on behalf of the Commission: 


\section{DISCLAIMER}

This report was prepared as an account of work sponsored by an agency of the United States Government. Neither the United States Government nor any agency Thereof, nor any of their employees, makes any warranty, express or implied, or assumes any legal liability or responsibility for the accuracy, completeness, or usefulness of any information, apparatus, product, or process disclosed, or represents that its use would not infringe privately owned rights. Reference herein to any specific commercial product, process, or service by trade name, trademark, manufacturer, or otherwise does not necessarily constitute or imply its endorsement, recommendation, or favoring by the United States Government or any agency thereof. The views and opinions of authors expressed herein do not necessarily state or reflect those of the United States Government or any agency thereof. 


\section{DISCLAIMER}

Portions of this document may be illegible in electronic image products. Images are produced from the best available original document. 
Creep experiments on ceramic materiats are often done in bending to avoid problems of gripping or buckling associated with tensile or compressive tests. Although experimentally facile, bending tests do not lend themselves easily to exact calculations of strains and strain rates from experimentally measured beam deflections and deflection rates. In practice, strains and strain rates are usually calculated from approximate geometrical or elastic relations.

For example, in the case of three point bending in which the total deflection is measured at the center of the beam (i.e., the load point), the following approximate geometrical relations are commonly used:

$$
\begin{aligned}
& \varepsilon=\frac{4 h}{L^{2}} y=K y \\
& \dot{\varepsilon}=\frac{4 h}{L^{2}} \dot{y}=K \dot{y}
\end{aligned}
$$

$\varepsilon=$ maximum strain in the outer fiber

$\dot{\varepsilon}=$ strain rate in the outer fiber

$y=$ measured deflection at the center of the beam

$\dot{y}=$ deflection rate at the center of the beam

$h=$ thickness of the beam

$L$. = distance between the support points.

In equations ( 1 ) and (2). the beam is assumed to have a constant radius of, curvature over its entire length. This situation is physically impossible because the bending moment varies between LP ( $P$ is the applied load) at the center and zero at the two support points.

Although three point bending tests are often performed, many investigators use a four point bending configuration. In this case, the ideal experimental 
procedure is one in which the deflection is measured:at the center of the beam relative to the two loading points. Equations (1) and (2) apply in this situation because the moment and, therefore, the radius of curvature of the beam are constant between the load points. However, the use of three probes requires larger specimens than are usually available in an experimental situation and so deflection and deflection rates are commonly measured at the load points relative to the support points. In this note, calculations of strains and strain rates from deflection data obtained by measurements at the load points are considered. This problem was undertaken initially to see if there was some reason inherent in four point bending tests why strain rates should decrease with increasing strain as has been observed in several bending creep studies on oxides. (1-5)

The following approximate elastic equations are commonly used to calculate strains and:strain rates from measurements of deflections and deflection rates at the load points in four point bending creep tests:

$$
\begin{aligned}
& \varepsilon=\frac{6 h}{(L-a)(L+2 a)} x=K^{\prime} x \\
& \dot{\varepsilon}=\frac{6 h}{(L-a)(L+2 a)} \dot{x}=K^{\prime} \dot{x}
\end{aligned}
$$

$x=$ deflection of the beam at the load points relative to the support points,

$\dot{x}=$ deflection rate at the load points relative to the support points,

$a=$ distance between the load points.

Since these equations are derived for the elastic deflection of beams, there is an implied assumption that $\varepsilon: \alpha \sigma$ ( $\sigma$ is the stress). They should, therefore, be approximately valid for calculating strains and strain rates 
under viscous creep (i.e., $\dot{\varepsilon} \alpha \sigma$ ) situations.

For nonviscous creep.(i.e., $\dot{\varepsilon} \alpha \sigma^{N}$ with $N>1$ ) the situation will be different. Because the moment varies from a constant value between the load points to zero at the support points, the radius of curvature of the beam must vary from a finite value at the load points to infinity at the support points. The manner in which the radius of curvature varies between these two locations will depend on the value of the creep exponent (N).

It would be ideal to calculate strains and strain rates based on the actual geometry of the deformed beam. However, the actual geometry of a deformed specimen during a creep test cannot be determined easily. Two geometries exist, however, for which calculations can be made and which will bracket all possible bending configurations. These are illustrated in Figures 1 and 2. They are, in the first case, the geometry described by a perfect circle everywhere between the support points; and, in the second case, one described by a perfect circle only between the load points and straight elsewhere. The first geometry describes the physically unreal condition in which the creep exponent is zero. The second geometry corresponds to a condition of a very large creep exponent $(N)$. Any real case will lie between these two extremes. In recent creep studies $(1,2)$ on polycrystalline magnesium oxide the geometries of the deformed beams were found to lie between these two conditions.

For the case in which the beam is completely circular between the support points, the following equations can be written from an inspection of Figure 1.

$$
\begin{aligned}
& z=r^{\prime}-(y-x) \\
& z=\sqrt{r^{12}-a^{2} / 4}
\end{aligned}
$$




$$
\begin{aligned}
r^{\prime}-y & =\sqrt{r^{32}-L^{2 / 4}} \\
r^{\prime} & =r-h / 2
\end{aligned}
$$

Equations (5) - (8) can be solved for $r$.

$$
r=r^{\prime}+h / 2=\frac{y^{2}+L^{2} / 4}{2 y}+h / 2
$$

The strain is

$$
\varepsilon=\frac{h}{2 r}=h\left[\frac{y}{y^{2}+h y+L^{2} / 4}\right]
$$

The strain rate is then

$$
\dot{\varepsilon}=\frac{d \varepsilon}{d t}=\frac{d \varepsilon}{d y} \frac{d y}{d t}=h\left[\frac{L^{2} / 4-y^{2}}{\left(y^{2}+L^{2} / 4+h y\right)^{2}}\right] \dot{y}
$$

For small strains $\left(y \ll L^{2} / 4\right)$ equations (10) and (11) are the same as. equations (1) and (2). For deflections measured at the load points y can be found in terms of $x$ : from equations (5), (6), and (9).

$$
y=\frac{x+a^{2} / 4 x-L^{2} / 4 x+\sqrt{\left(x+a^{2} / 4 x-L^{2} / 4 x\right)^{2}+L^{2}}}{2}
$$

Equation (12) can be combined with equation (10) to calculate strains from measured deflections at the load points. The strain rate in terms of $x$-deflection is given by (13). and (14):

$$
\dot{\varepsilon}=\frac{d \varepsilon}{d y} \frac{d y}{d x} \frac{d x}{d t}=h\left[\frac{L^{2} / 4-y^{2}}{\left(y^{2}+L^{2} / 4+h y\right)^{2}}\right] \frac{d y}{d x} \quad \dot{x}
$$




$$
\frac{d y}{d x}:=1 / 2 \cdot\left[1+\frac{L^{2}}{4 x^{2}}-\frac{a^{2}}{4 x^{2}}+\frac{\left(x+a^{2} / 4 x-L^{2} / 4 x\right)\left(1+L^{2} / 4 x^{2}-a^{2} / 4 x^{2}\right)}{\sqrt{\left(x+a^{2} / 4 x-\because L^{2} / 4 x\right)^{2}+L^{2}}}\right]
$$

For the geometrical case in which a perfect circle exists only between the load points and the beam is straight elsewhere, the following equations can be written from an inspection of Figure 2 .

$$
\begin{aligned}
& r^{\prime 2}=a^{2} / 4+\left(r^{1}-y+x\right)^{2} \\
& R^{2}=p^{2}+r^{\prime 2} \\
& p^{2}=[(L-a) / 2]^{2}: x^{2} \\
& R^{2}=(L / 2)^{2}+\left(r^{\prime}-y\right)^{2}
\end{aligned}
$$

By elimination of variables $r$ can be obtained in, terms of the $x$-deflection leading to the following equation for the strain.

$$
\varepsilon=\frac{h}{2 r}=\frac{h}{\sqrt{\left(1 / 4 x^{2}\right)\left[L a-a^{2}\right]^{2}+a^{2}}+h}
$$

The strain rate is

$$
\dot{\varepsilon}=\frac{d \varepsilon}{d r} \cdot \frac{d r}{d x}: \frac{d x}{d t}:=-\frac{h}{2 r^{2}} \frac{d r}{d x} \cdot \dot{x}
$$

in which

$$
\frac{d r}{d x}=-\frac{\left(1 / 16 x^{3}\right)\left(L a-a^{2}\right)^{2}}{\sqrt{\left(1 / 16 x^{2}\right)\left(L a-a^{2}\right)^{2}+a^{2} / 4}}
$$

The strain rate is given by equation (22) 


$$
\dot{\varepsilon}=\frac{h}{2} \cdot\left[\frac{1}{\left(\sqrt{\left(1 / 16 x^{2}\right)\left(L a-a^{2}\right)+a^{2} / 4}+h / 2\right)^{2}}\right]\left[\frac{\left(1 / 16 x^{3}\right)\left(L a-a^{2}\right)^{2}}{\sqrt{\left(1 / 16 x^{2}\right)\left(L a-a^{2}\right)^{2}+a^{2} / 4}}\right] \dot{x}
$$

The foregoing equations ignore subtleties such as the effect of Poisson's ratio and the location of the line of no strain (assumed to be in the center of the sample) and experimental difficulties such as indentation of the sample by the load and support points and slippage of the sample at these points. It is assumed that these effects are secondary.

To determine what the equations predict for $\varepsilon$ and $\dot{\varepsilon}$, specific calculations were performed assuming typical values for $h, L$ and a. $(1,2)$

$$
\begin{aligned}
& \mathrm{h}=0.191 \mathrm{~cm} \\
& \mathrm{~L}=1.905 \mathrm{~cm} \\
& \mathrm{a}=\mathrm{L} / 2=0.95025 \mathrm{~cm}
\end{aligned}
$$

Using these values $K^{\prime}\left(=\frac{\varepsilon}{\mathrm{x}}=\frac{\dot{\varepsilon}}{\dot{\mathrm{x}}}\right)$ was calculated from equation 3. "Elastic" strains based on this value are plotted in Figure 3 along with strains obtained from equations (10) and (12) and equation (19). as a function of. $x$-deflection. The maximum error which can occur at the $2 \%$ strain level using the elastic approximation (equation 3) in the calculation of strain from $x$-deflection is about $25 \%$. In real cases this error is lower. It is of interest that the strain calculated from equation (3) lies between the values for the two limiting cases.

In Figure 4 strain rates which are based on these two geometrical extremes are plotted using equations (13) and (14) and equation (22). The function $\dot{\varepsilon} / \dot{x}$ is plotted against total $x$ deflection. $\dot{\varepsilon} / \dot{x}$ is a constant 
(0.316) in equation (4). The actual value of the strain rate calculated from either geometry decreases (if the deflection rate remains constant) as strain increases. For the completely circular geometry, the elastic approximation progressively overestimates the strain rate by significant amounts as the strain increases. For the partly circular geometry, the elastic assumption underestimates the strain rate until about. $6 \%$ strain. after which it progressively overestimates the strain rate. Again, strain rates calculated from the elastic approximation lie intermediate to the two 1 imiting geometries for strains under $6 \%$.

At the $2 \%$ strain level in both cases $\dot{\varepsilon} / \dot{x}$ has decayed by about $7 \%$. Thus, for small strains the approximation $\dot{\varepsilon} \alpha \dot{x}$, which is frequently used, $(1,2)$ is quite reasonable.

Finally, it is noted that if the deflection rate is experimentally observed to decrease with increasing strain (time), then the strain rate must decrease even more rapidly. with time. Therefore, an observed decay in the strain rate with increasing strain is not peculiar to four point bending itself, but it is a material related phenomenon.

\section{ACKNOWLEDGEMENTS}

The support of the research by the Atomic Energy Commission under Contract AT(11-1)-1591 is gratefully acknowledged. The principal author is grateful for the partial support of a National Science Foundation Traineeship. The authors are grateful for the helpful discussions with Dr. John B. Wachtman, Jr. 


\section{REFERENCES}

1. G. R. Terwilliger, "Creep of Polycrystalline Magnesia", unpublished Ph.D. thesis, University of Utah, August 1968.

2. G. R. Terwilliger and R. S。 Gordon, "The Creep of Polycrystall ine Magnesium Oxide and $\mathrm{MgO}-\mathrm{Fe}_{2} \mathrm{O}_{3}$ Solid Solutions at Elevated Temperatures," J. Am. Ceram. Soc. (in press).

3. E. M. Passmore, R. H. Duff and R. M. Spriggs, "Creep of Dense Polycrystalline Magnesium Oxide," J. Am. Ceram. Soc. 49 (11) 594-600 (1966).

4. H. Tagai and T.Zisner, "High Temperature Creep of Polycrystalline Magnesia: I. Effect of Simultaneous Grain Growth," $\underline{\text { J }}$ Am. Ceram. Soc. 51 (6) 303-10 (1968).

5. E. M. Passmore and T. Vasilos; "Creep of Dense, Pure, Fine-Grained Ai uminum Oxide," J. Am. Ceram. Soc. $\underline{49}$ (3) 166-8 (1966). 


\section{LIST OF FIGURES}

Figure 1

Figure 2

Figure 3

Figure 4
Schematic-Completely Circular Bending

Schematic-Partly Circular Bending

A Comparison of Strain Versus Deflection for the Elastic, Completely Circular and Partly Circular approximations

$\dot{\varepsilon} / \dot{x}$ Versus Strain for the Elastic, Completely Circular, and Partly Circular Approximations 


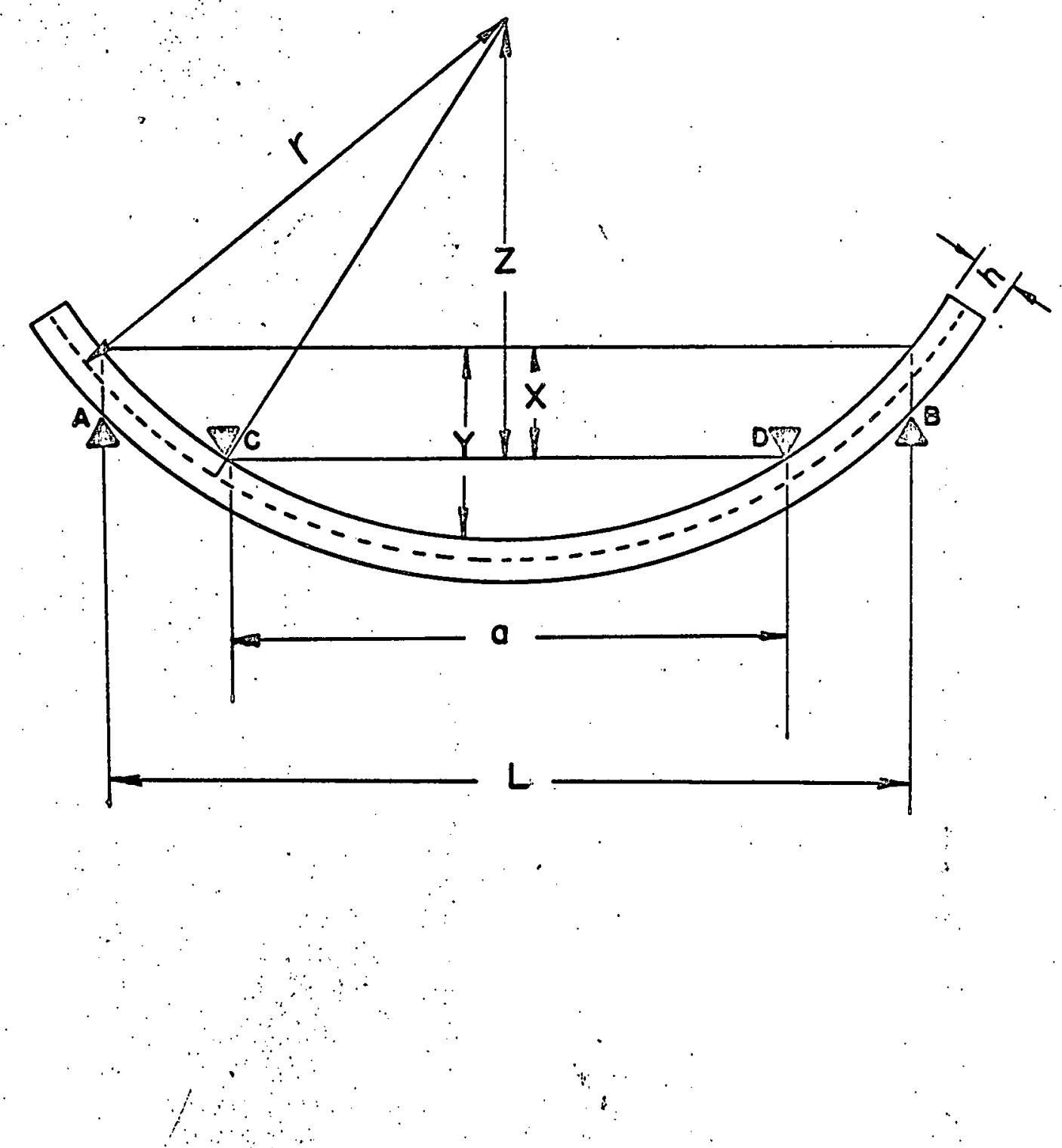

Figure 1. Schematic-Cómpletely Circular Bending 


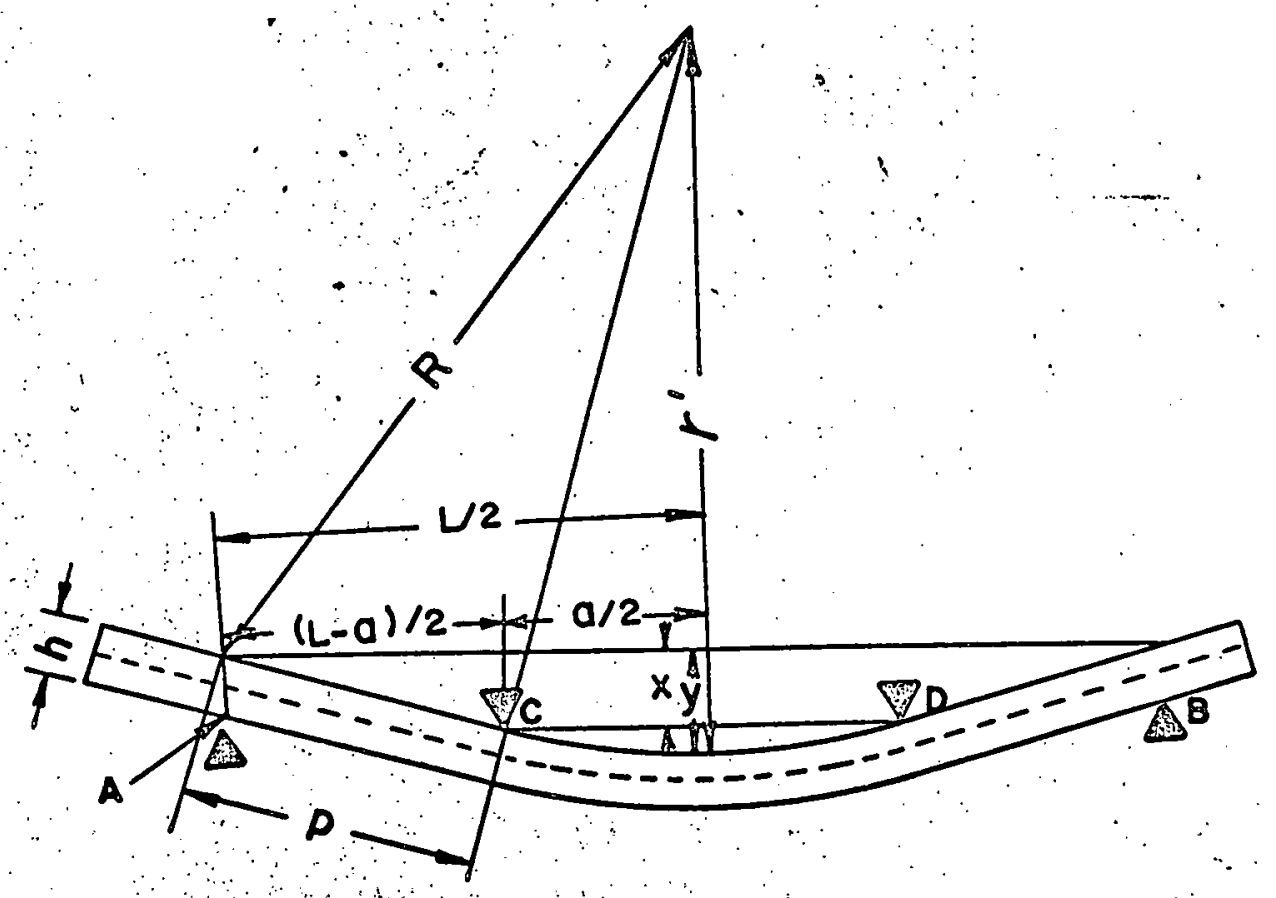

Figure 2 Schematic-Partly Circular Bending

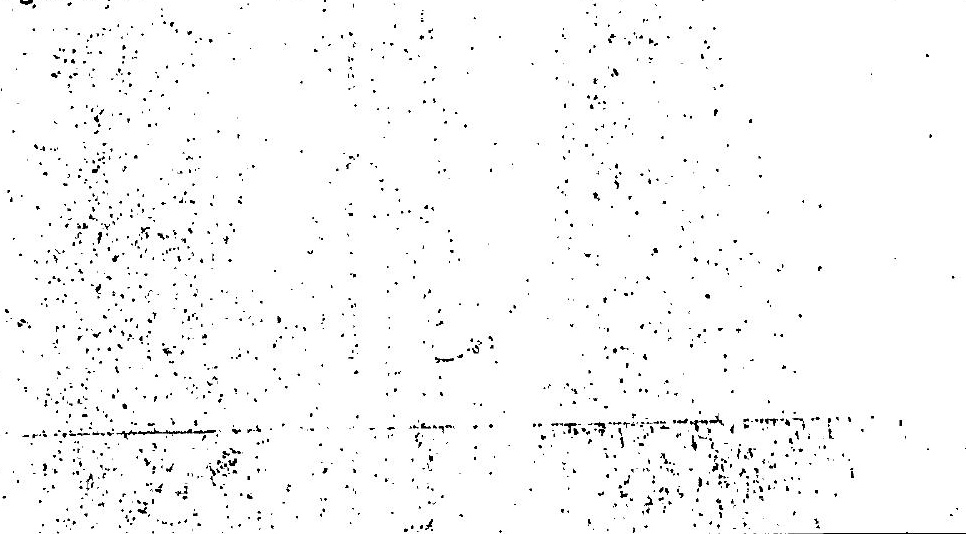




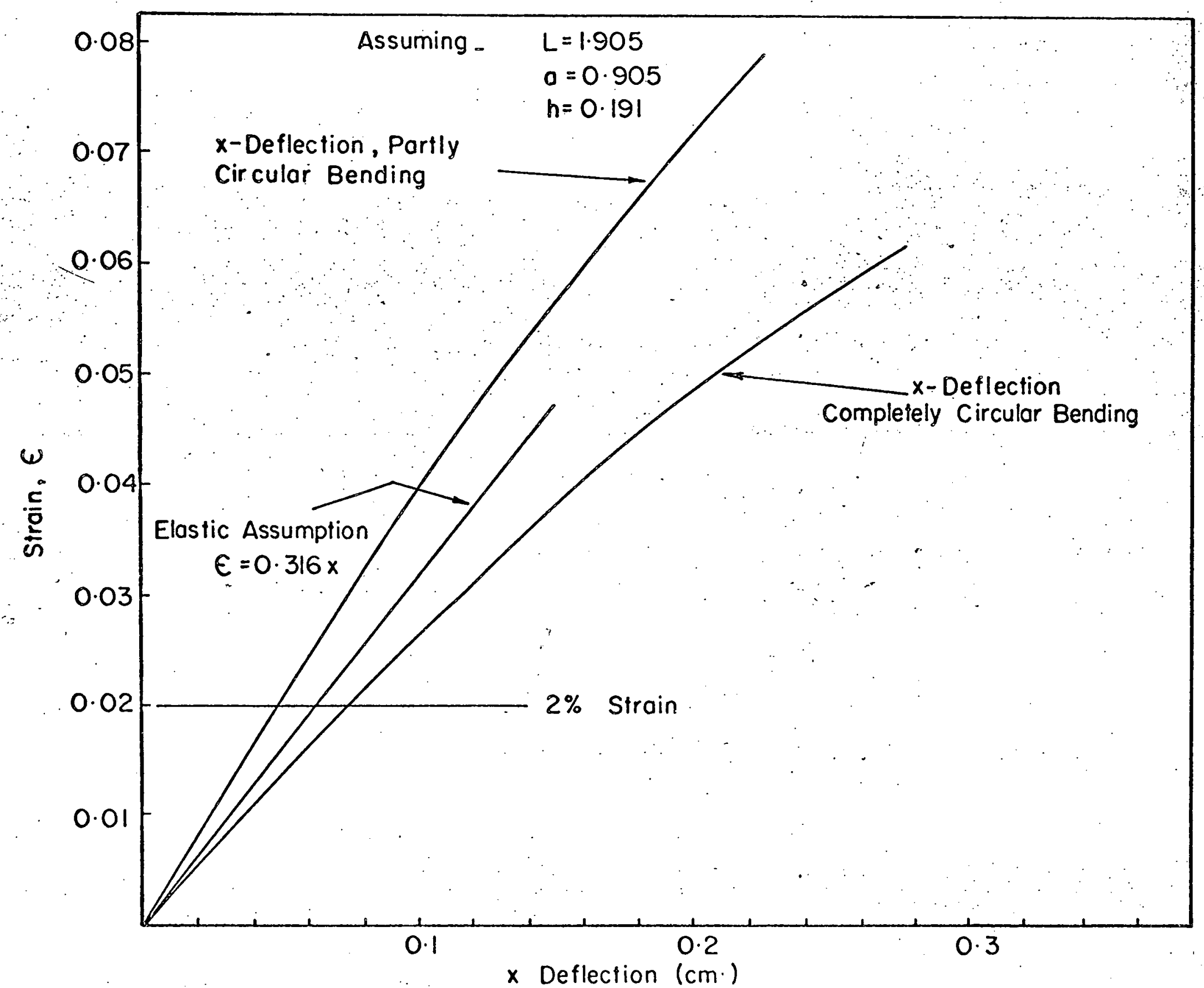

Figure 3 A Comparison of Strain Versus Deflection for the Elastic, Completely Circular and Partly Circular Approximations 


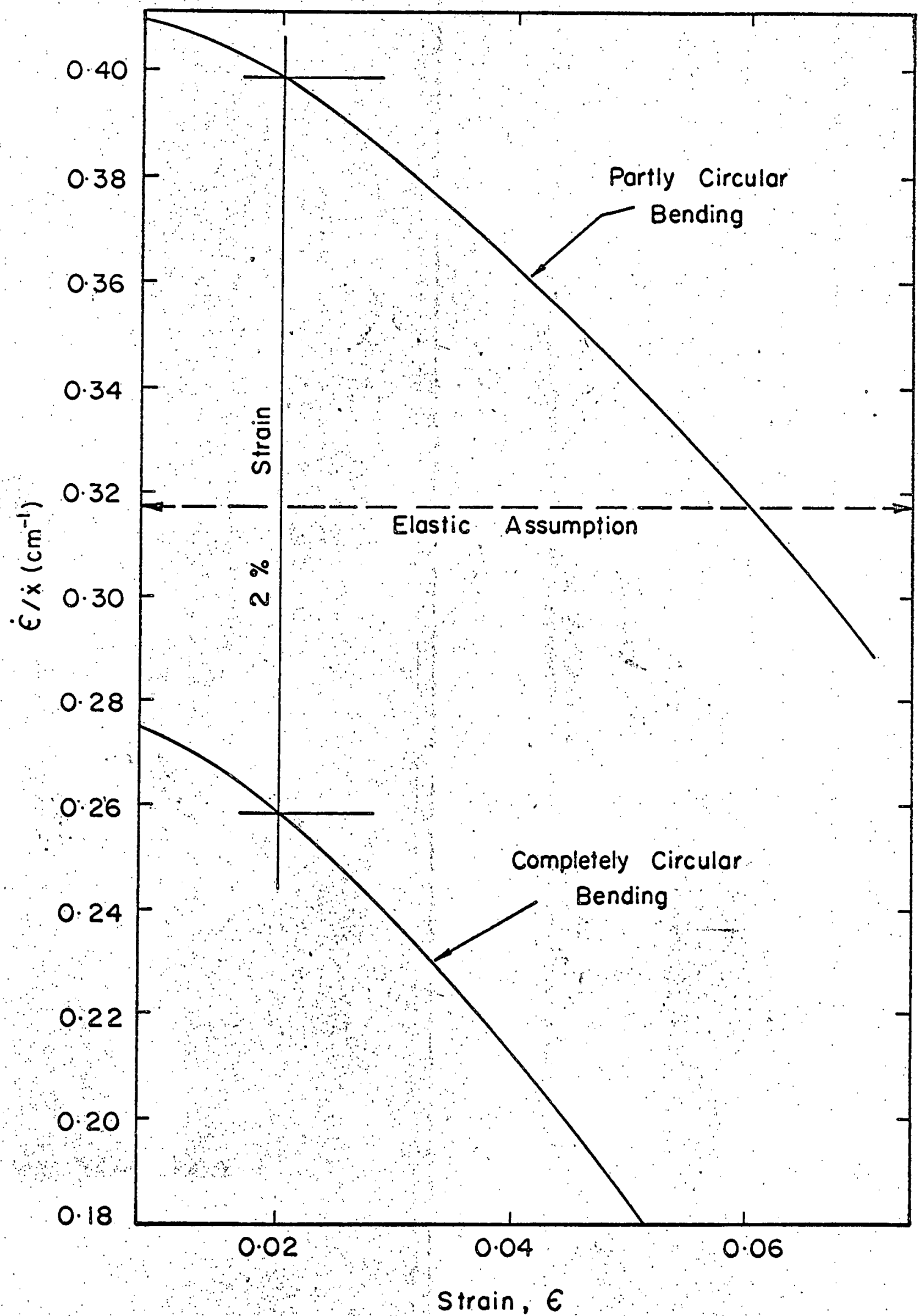

Figure 4 yersus Strain for the Elastic, completely circular, and Partly Circular Approximations 